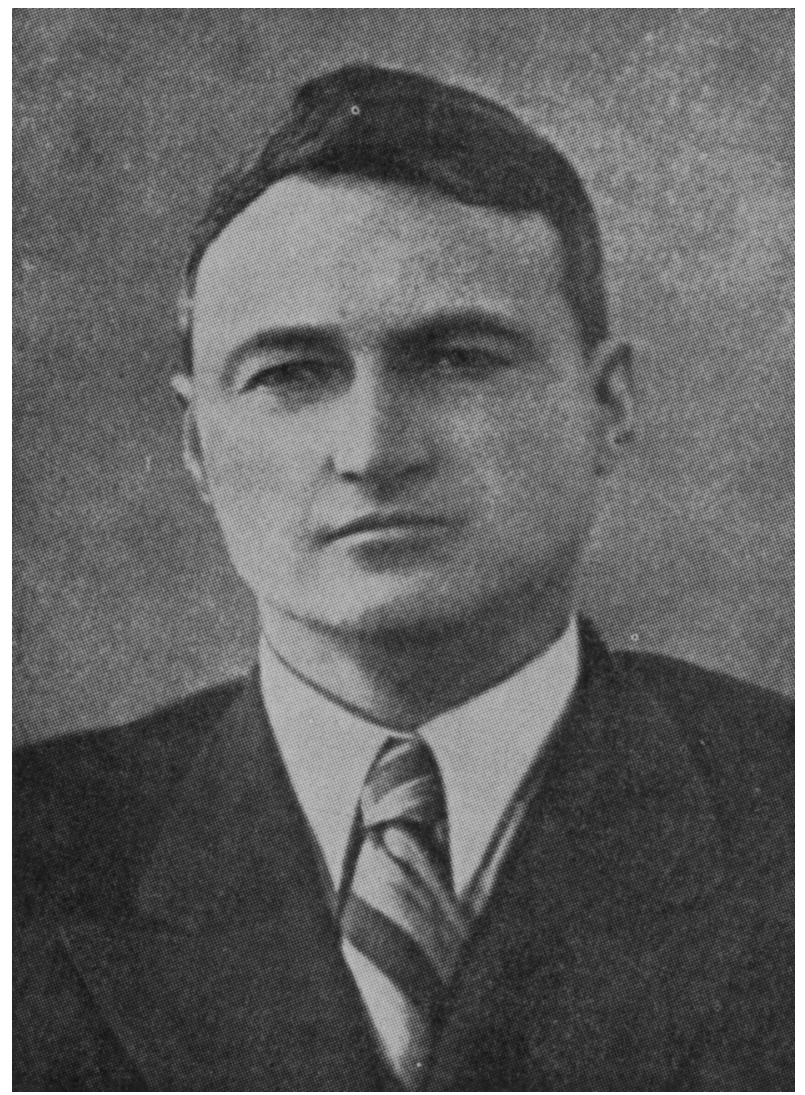

YU. V. LINNIK 1915-1972 


\section{Obituary: YU. V. LINNIK}

Yurii Vladimirovich Linnik, an editor of this journal, was born on the eighth of January 1915 at Belaya Tserkov' in the Ukraine. He graduated from the University of Leningrad in 1938 and obtained his Doctorate in Science at the unusually early age of twenty-five. He served as a Major in Artillery Survey during the war and took part in the terrible siege of Leningrad; afterwards he always felt a great affection for his comrades of his army days. His scientific life was spent in the Steklov Institute in Leningrad and at Leningrad University where he was appointed professor in 1944. He became a corresponding member of the USSR Academy of Sciences in 1953 and a full member in 1964.

His early interest was in algebraic and analytic number theory and an account of this work appears in the reference at the end of this obituary. However he soon turned his attention to probability theory and to the very deep analytical theories which underlie, in a concealed manner, many of the classical problems of statistics.

He studied extensions of the central limit theorem to dependent chains and the probability of large deviations. This led him to a deep understanding of characteristic functions and thus to the problem of the decomposition of distributions to which he made many contributions and on which he wrote a book. He also wrote many papers on characterisation theorems and succeeded, by an exceedingly complicated method, in proving the classical central limit theorem by using the concept of entropy. He then tried to prove Cramér's characterisation theorem by using entropy but like so many others who have tried this problem, did not succeed. Later he became more interested in statistical problems and wrote on similar regions, the Behrens-Fisher problem (for which he proved that smooth nonrandomised tests do not exist), and nuisance parameters in general. On all these he obtained deep and important results which he incorporated into a book. Only Linnik would have the power and originality to apply sheaf theory to the Behrens-Fisher problem. As a result of this work he founded a flourishing school of mathematical statistics at Leningrad. Except for three papers on the theory of polishing surfaces, he did not do any applied work, but both in number and probability theory he worked only on extremely difficult problems and published 
at an extraordinary rate. A bibliography of 171 items published up to 1964 will be found in the reference. No attempt is made here to list his many publications since that date.

Linnik was devoted to his family and his country. He also had an extremely strong and pungent sense of humour, and wrote much comic verse, both in Russian and English. No one who was at the dinner at the Fifth Berkeley Symposium will forget his reading a tribute in verse to Professor Elizabeth Scott which, I trust, is securely preserved in the archives of that University. He also had a great devotion to the works of P. G. Wodehouse and it was his ambition, finally achieved, to possess a complete set of all his writings. I remember many happy hours spent in shabby San Francisco second-hand bookshops helping him to look for copies he did not possess.

We have lost a great scientist, and many of us a great friend.

P. A. P. MORAN

Department of Statistics

Australian National University, Canberra

\section{References}

Ibragimov, I. I., Malyshev, A. V. AND Petrov, V. V. (1965) Yurii Vladimirovich Linnik (On his fiftieth birthday). Russian Mathematical Surveys (English translation). 20, part 2, 153-168. 